\title{
The spawning strategy of European hake (Merluccius merluccius, L. 1758) across the Western and Central Mediterranean Sea
}

\author{
Pierluigi Carbonara $^{\mathrm{a}, *}$, Cristina Porcu ${ }^{\mathrm{b}}$, Marilena Donnaloia ${ }^{\mathrm{a}}$, Paola Pesci ${ }^{\mathrm{b}}$, Letizia Sion ${ }^{\mathrm{c}}$, \\ Maria Teresa Spedicato $^{a}$, Walter Zupa ${ }^{a}$, Francesca Vitale ${ }^{\mathrm{d}}$, Maria Cristina Follesa ${ }^{\mathrm{b}}$ \\ ${ }^{a}$ COISPA Tecnologia \& Ricerca, Stazione Sperimentale per lo Studio delle Risorse del Mare, Dei Trulli 18/20, 70126, Bari, Italy \\ ${ }^{\mathrm{b}}$ Department of Life and Environmental Sciences, Division of Animal Biology and Ecology, University of Cagliari, T. Fiorelli, 09126, Cagliari, Italy \\ ${ }^{c}$ Department of Biology, University of Bari, Via Orabona, 4, 70100, Bari, Italy \\ ${ }^{\mathrm{d}}$ Swedish University of Agricultural Sciences, Department of Aquatic Resources, Institute of Marine Research, Turistgatan 5 S-453 30 Lysekil, Sweden
}

\section{A R T I C L E I N F O}

Handled by Bent Herrmann

Keywords:

Merluccius merluccius

Spawning strategy

Macroscopic maturity scale

Histology

Mediterranean Sea

\begin{abstract}
A B S T R A C T
The oocyte maturation and spawning pattern of European hake Merluccius merluccius, one of the most important species in the Mediterranean fishery, were investigated using data collected in a scientific trawl survey (Mediterranean International Trawl Survey, MEDITS) as well as commercial landing data collected in several geographical sub-areas (GSAs): the Southern and Central Tyrrhenian Sea (GSA10), Sardinia (GSA11), the Southern Adriatic Sea (GSA18) and the Western Ionian Sea (GSA19). The lack of the validation of macroscopic maturity scales is one impediment to obtaining reliable estimates of the reproductive parameters used to assess a fish stock. The MEDITS maturity scale was validated for female European hake by histological analysis of the oocyte diameter frequency distributions and according to the gonadosomatic index. The oocyte diameter frequency distributions and histological analysis confirmed that the ovarian organisation of hake was asynchronous, including a batch spawning pattern and indeterminate fecundity.

Females in spawning condition were recorded throughout the year in all GSAs although the main peaks of spawning activity were in winter and in late summer and early autumn. The $\mathrm{L}_{50}$ estimated for GSA10, GSA11, GSA18, GSA19 were $33.03 \mathrm{~cm}, 30.03 \mathrm{~cm}, 31.95 \mathrm{~cm}$ and $32.95 \mathrm{~cm}$, respectively. Moreover, no significant trends in the annual estimate of $\mathrm{L}_{50}$ from 2007 to 2015 in any of the study areas were observed. Mean batch fecundity and relative fecundity (360,687 eggs/fish, $281.6 \mathrm{eggsg}^{-1}$ in GSA10, 361,311 eggs/fish, and $262.2 \mathrm{eggs} \mathrm{g}^{-1}$ in GSA18) were higher than those reported in other Mediterranean areas.
\end{abstract}

\section{Introduction}

A primary goal of fishery management is to allow sustainable exploitation by maintaining a spawning stock biomass level that is suitable to ensure population renewal (Beverton and Holt, 1957). For this reason, the knowledge of reproductive traits, such as fecundity, length at maturity and spawning cycle, is essential to quantify the reproductive capacity at both individual and population levels (Murua and Saborido-Rey, 2003).

The status of the most Mediterranean marine fishery resources exceed safe biological limits, particularly for the European hake (Merluccius merluccius, Linnaeus, 1758), which is presently deemed overfished in several areas (Cardinale et al., 2011; Abella et al., 2013; GFCM, 2014). This species is caught in the Mediterranean by different methods, such as bottom trawls, longlines and gillnets (Follesa et al.,
2011; Cardinale et al., 2015a). Between 2004 and 2011 in Italian waters, the catches of hake were the lowest in 2004 (about 9600 tonnes) and the highest in 2006 (about 19,000 tonnes). In the other years during this period, the catches were on average about 14,000 tonnes (Cardinale et al., 2015b). The Adriatic landings have represented an average of $26 \%$ of the total Italian catches (FishStat Plus, 2012). Despite the economic and ecological importance of hake, gaps in our understanding of reproductive biology still exist for some Mediterranean areas, specifically in the Southern Adriatic Sea, the Southern and Central Tyrrhenian Sea, and the Ionian and Sardinian Seas.

The European hake is a multiple batch spawner with indeterminate fecundity (i.e. the number of eggs produced annually is not fixed at the beginning of the spawning season but is the result of the continuous recruitment of new batches of unyolked oocytes in the ovary), which is associated with the asynchronous development of the oocytes (Murua

\footnotetext{
* Corresponding author.

E-mail address: carbonara@coispa.it (P. Carbonara).
} 
et al., 1998; Sarano, 1984). Species that use this strategy generally produce a larger number of eggs compared to those that use determinate fecundity (Murua and Saborido-Rey, 2003). Moreover, in the Mediterranean Basin, hake is a partial spawner with a very long reproductive period with multiple peaks throughout the year (e.g. Reňones et al., 1995; Recasens et al., 2008; Al-Absawy, 2010). To date, very few studies on reproductive biology using macroscopic versus microscopic approaches have been undertaken although a few studies have been conducted in the Western and Central Mediterranean (Reňones et al., 1995; Recasens et al., 2008; Al-Absawy, 2010). The gaps in the knowledge can be attributed to the lack of a validated maturity scale (ICES, 2014) that allows precise estimates of stock spawning components.

For demersal fish species, such as $M$. merluccius, their potential fecundity (i.e. the number of vitellogenic oocytes eventually spawned as eggs), is strongly related to body length (Murua et al., 2003). The largest females produce the highest numbers of eggs of higher quality (Carbonara et al., 2015), and females in good health exhibit higher fecundity (Kjesbu, 1989; Ferrer-Maza et al., 2014). Fishing pressure can affect the reproductive potential of a stock because biological traits, such as size, age at maturity and fecundity, could cause plastic or genetic changes in response to fishing (Trippel, 1995; Cardinale and Modin, 1999; Hutchings and Reynolds, 2004). For exploited populations, the largest and oldest females are eliminated more rapidly because they are exposed to size-selectivity fishing mortality. Moreover, variations in the reproductive parameters and dynamics of fish populations substantially affect egg availability (Godo and Haug, 1999; Korta et al., 2010; Mehault et al., 2010). An analysis of temporal variations in inter- and intra- population levels would contribute to a better understanding of the reproductive aspects of hake in the Mediterranean, thus providing information regarding the estimation of the biological indicators related to fishing pressure (Trippel, 1995).

The Mediterranean International Trawl Survey (MEDITS) is a scientific bottom trawl survey designed in response to the European Commission's initiative to produce biological data on the demersal resources in the Mediterranean Sea from 10 to $800 \mathrm{~m}$ depth (Bertrand et al., 2002). The results of this survey are a relevant source of homogeneous data with accurate standardisation, long time series and broad spatial coverage (AAVV, 2017), providing valuable measures of relative abundance, rates of population change as well as sex and size composition in a wide range of species (Rago, 2005).

Despite the economic and ecological importance of hake and the depletion of the European stocks, studies on hake's reproductive potential in the Mediterranean Basin are scarce (Murua et al., 1998). Hence, the objectives of the present study are as follows: 1) validate the MEDITS macroscopic maturity scale through histology and morphometric oocyte analysis; 2) increase the knowledge of the reproductive aspects of hake populations in the Western and Central Mediterranean in terms of the reproductive cycle (spawning season and peaks) and potential fecundity estimates; 3 ) estimate lengths at maturity $\left(L_{50}\right)$ in different Mediterranean areas as well as $L_{50}$ temporal trends using the MEDITS data; and discuss outcomes from the point of view of fishery management.

\section{Materials and methods}

\subsection{Sampling}

Females were collected from bottom trawl, longline and gillnet fisheries in the four geographical sub-areas (GSA according to the FAO classification: GFCM-geographical sub-areas) analysed: the Southern and Central Tyrrhenian Sea (GSA10), Sardinia (GSA11), the Southern Adriatic Sea (GSA18) and the Western Ionian Sea (GSA19) (Fig. 1). The sampling was conducted during several research and monitoring projects: bottom trawl surveys (MEDITS, AAVV, 2017) in the spring and summer months in the periods 2007-2015 in GSA 10 and GSA 19,
2009-2015 in GSA 18 and 2012-2015 in GSA 11. Samples of commercial landings (Data Collection Framework-DCF, EU Reg. 199/2008) were collected monthly in 2014-2015 in GSAs 10, 18 and 19 and from 2012 to 2015 in GSA11.

For each female specimen the following parameters were measured: total length (TL, cm) to the nearest half $\mathrm{cm}$; total weight (TW, g) to the nearest $0.1 \mathrm{~g}$; and sex and ovary maturation. Macroscopic maturity stages were determined according to the MEDITS scale (AAVV, 2017) (Table 1). For a subsample of females, gutted weight (GW) to the nearest $0.1 \mathrm{~g}$, liver weight (LW) and gonad weight (GoW, g), both to the nearest $0.01 \mathrm{~g}$, were also recorded. The number of females sampled and the relative range in total length for each GSA are summarised in Table 2.

\subsection{Oocyte development}

A subsample of five ovaries in each maturity stage was processed for histological analysis. The samples were first stored in 5\% buffered formaldehyde $\left(0.1 \mathrm{~mol} 1^{-1}, \mathrm{pH} \mathrm{7.4)}\right.$ for a maximum $48 \mathrm{~h}$. They were then dehydrated, embedded in synthetic resin (GMA, Technovit 7100, Bio-Optica) according to routine protocols and sectioned at $3.5 \mu \mathrm{m}$ using a rotary microtome (LKB, Historange). The slides were stained with haematoxylin and eosin (H\&E) for the standard histology (Cerri and Sasso-Cerri, 2003). The oocyte developmental stages were identified according to the scale proposed by Brown-Peterson et al. (2011) using an optic microscope (Laborlux 12) at original magnification $40-400 \times$. The size-frequency distribution of the oocytes was developed for specimens taken from GSA18. The diameters of the oocytes (10 ovaries with 200 measures of each ovary) were measured only for oocytes where the nucleus was clear, and the maximum and minimum diameters were averaged when the shape was not spherical.

\subsection{Batch fecundity}

Batch fecundity (BF), which is defined by the number of early and fully hydrated oocytes released in a mature batch for each individual, was estimated for mature/spawning females (stage 3) in GSA10 $(\mathrm{N}=109)$ and GSA18 $(\mathrm{N}=45)$. Three samples of ovary tissue were taken from the two lobes (anterior, middle and posterior positions), weighed (nearest $0.001 \mathrm{~g}$ ) and then fixed in $5 \%$ buffered formalin. The hydrated oocytes were counted in a subsample for each portion, and the $\mathrm{BF}$, estimated according to the gravimetric method (Hunter et al., 1985; Murua et al., 2003), was extrapolated from the gonad weight according to the following relationship (Carbonara et al., 2015):

$B F=\frac{\left(n W_{\text {for }} *\left(W_{\text {for-sub }} / W_{\text {for }}\right)\right)}{W_{\text {fre }}} * G o W$

where $n W_{f o r}$ is the number of oocytes counted in the subsample of gonad preserved in formalin; $W_{\text {for-sub }}$ is the weight of the subsample; $\mathrm{W}_{\text {for }}$ is the total weight of the sample preserved in formalin; $\mathrm{W}_{\text {fre }}$ is the weight of the fresh sample; and GoW is the total ovary weight.

The relative BF was calculated as the number of hydrated oocytes per gram of gutted weight. The relationships between BF and TL, TW and GW were estimated by regression analyses.

\subsection{Spawning cycle}

The spawning cycle of the species was studied in the investigated areas by analysing the monthly occurrences of maturity stages and the monthly trends in the gonadosomatic (GSI) and hepatosomatic (HSI) indices. The values of GSI and HSI for the adult portion of the female population (stages $2 \mathrm{~b}-4 \mathrm{~b}$ ), respectively, were calculated as follows:

$G S I=\left(\frac{G o W}{G W}\right) * 100$ 


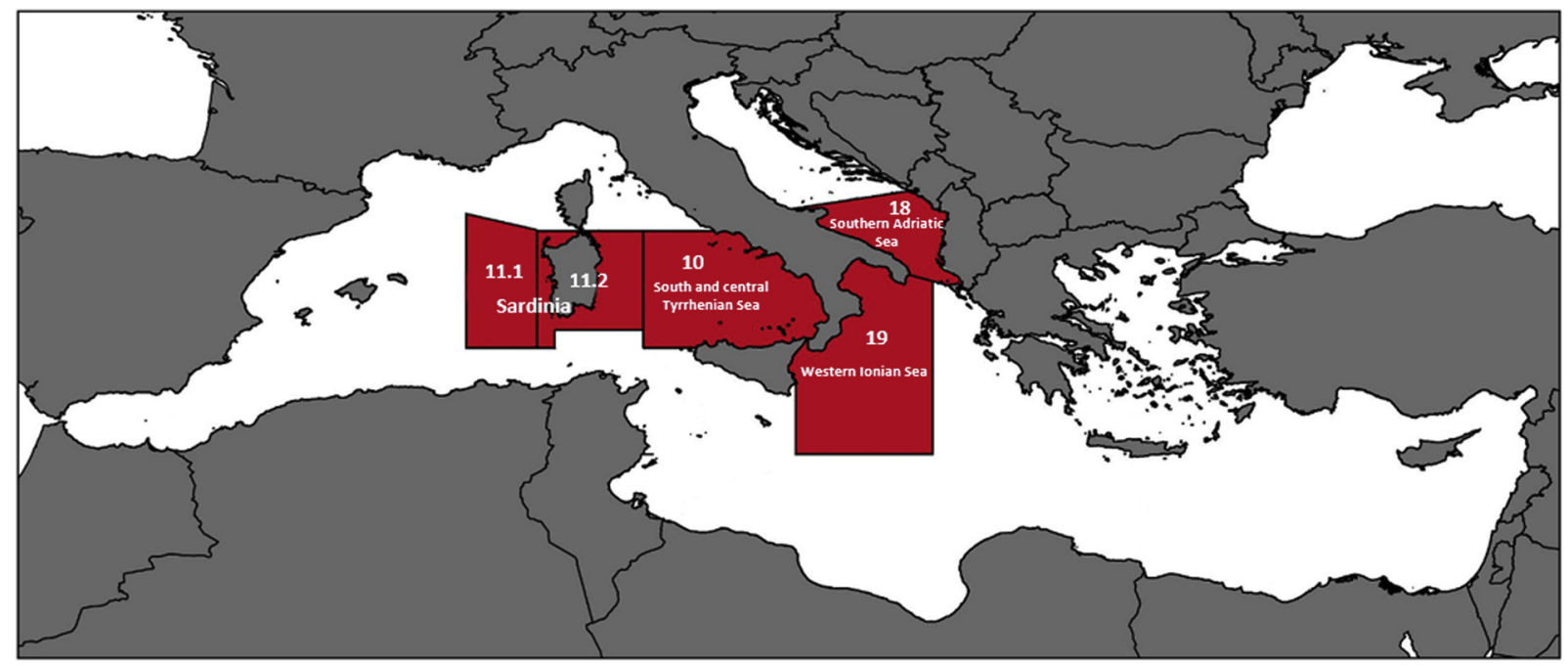

Fig. 1. Geographical sub-areas (GSA) involved in this study.

Table 1

MEDITS maturity scale for Undetermined (I) and Female (F) bony fish.

\begin{tabular}{|c|c|c|c|}
\hline Sex & Stage & Maturation state & Gonad Aspect \\
\hline I & 0 & UNDETERMINED & Sex undetermined to the naked eye. Gonad very small and translucid, almost transparent \\
\hline $\mathrm{F}$ & 1 & IMMATURE - VIRGIN & Small pinkish and translucent ovary shorter than $1 / 3$ of the body cavity. Eggs not visible to the naked eye \\
\hline $\mathrm{F}$ & $2 \mathrm{a}$ & VIRGIN - DEVELOPING & Small pinkish/reddish ovary, shorter than $1 / 2$ of the body cavity. Eggs are not visible to the naked eye \\
\hline $\mathrm{F}$ & $2 \mathrm{~b}$ & RECOVERING & Pinkish-reddish/reddish-orange and translucent ovary about $1 / 2$ of the body cavity. Eggs not visible to the naked eye \\
\hline $\mathrm{F}$ & $2 \mathrm{c}$ & MATURING & $\begin{array}{l}\text { Ovary pinkish-yellow in colour with granular appearance, long about } 2 / 3 \text { of the body cavity. Eggs are visible to the naked eye through the } \\
\text { ovaric tunica, which is not translucent yet. Under light pressure, eggs are not expelled. }\end{array}$ \\
\hline $\mathrm{F}$ & 3 & MATURE/SPAWNER & $\begin{array}{l}\text { Ovary orange pink in colour, with conspicuous superficial blood vessels, long from } 2 / 3 \text { to full length of the body cavity. Large transparent, } \\
\text { ripe eggs are clearly visible and could be expelled under light pressure. In more advanced conditions, eggs escape freely. }\end{array}$ \\
\hline $\mathrm{F}$ & $4 a$ & SPENT & $\begin{array}{l}\text { Reddish ovary shrunk to about } 1 / 2 \text { length of the body cavity. Flaccid ovary may contain remnants of disintegrating opaque and/or } \\
\text { translucent eggs. }\end{array}$ \\
\hline $\mathrm{F}$ & $4 \mathrm{~b}$ & RESTING & Pinkish and translucent ovary long about $1 / 3$ of the body cavity. Eggs are not visible to the naked eye. \\
\hline
\end{tabular}

Table 2

Summary of number of Merluccius merluccius females sampled, number of females used in Size at maturity $\left(\mathrm{L}_{50}\right)$ and range in Total length (TL) for each Geographical sub-area (GSA) studied.

\begin{tabular}{lclll}
\hline Area & GSA & $\begin{array}{l}\text { Number of } \\
\text { females } \\
\text { sampled }\end{array}$ & $\begin{array}{l}\text { Number of } \\
\text { females } \\
\text { in L } L_{50}\end{array}$ & $\begin{array}{l}\text { Range in } \\
\text { TL } \\
(\mathrm{cm})\end{array}$ \\
\hline $\begin{array}{l}\text { South and central } \\
\quad \text { Tyrrhenian Sea }\end{array}$ & 10 & 2555 & 1602 & $17.5-88.0$ \\
$\begin{array}{l}\text { Sardinia } \\
\text { Southern Adriatic Sea }\end{array}$ & 11 & 2628 & 2522 & $18.6-83.3$ \\
Western Ionian Sea & 18 & 8035 & 4202 & $17.0-93.5$ \\
\hline
\end{tabular}

$H S I=\left(\frac{L W}{G W}\right) * 100$

\subsection{Length at maturity}

The lengths at maturity $\left(\mathrm{L}_{50}\right.$, the length at which $50 \%$ of the population is adult) and the maturity range ( $M R=\mathrm{L}_{75}-\mathrm{L}_{25}$; the difference between the lengths at which $75 \%$ and $25 \%$ of the population is adult) were estimated for the females using a binomial generalised linear model (GLM, R Core Team, 2017) with a logistic link (ICES, 2008). According to the maturity scale, the specimens were considered adult if they were classified as $2 b, 2 c, 3,4 a$ and $4 b$, whereas they were considered immature if they were classified as 1 (immature-virgin) and 2a (virgin developing). The number of females used in the estimation of $\mathrm{L}_{50}$ utilising the MEDITS jointly to the landing and the discard data are reported in Table 2.
The MEDITS survey data were used to investigate the $\mathrm{L}_{50}$ temporal trends (2007-2015 for GSAs 10, 11 and 19 and 2009-2015 for GSA18). The rho Spearman correlation coefficient was used to evaluate whether a significant variation in the lengths at first maturity occurred in the considered time series.

\subsection{Data analysis}

The monthly averaged GSI values and the GSI of each maturity stage were estimated as \pm standard error (S.E.). The GSI mean values were investigated and compared among the maturity stages by a non-parametric Kruskal-Wallis test and a relative post-hoc Nemenyi test using $R$ software (R Core Team, 2017).

To investigate the relationships between batch fecundity and TL, TW and GW, regression analyses were performed for which the significance was evaluated by the analysis of the regression variance. The Chen test (Chen et al., 1992) was used for the statistical comparison of the exponential curve and to determine the relationship between $\mathrm{BF}$ and TL in GSAs 10 and 18. The linear relationships (batch fecundity with TL and GW) were statistically compared between GSAs (10 and 18) by covariance analysis.

The results of the ogive model of $L_{50}$ in the four GSAs $(10,11,18$ and 19) were statistically compared using a Chen test (Chen et al., 1992). 
Table 3

Oocyte development stages of European hake Merluccius merluccius. A brief description of each oocyte stage and its range size are given.

\begin{tabular}{ll}
\hline Oocyte development stage & Description \\
\hline Oogonia (OO) & $\begin{array}{l}\text { Small and round with a translucent cytoplasm and a large nucleus } \\
\text { (Fig. 1A) cytoplasm and a large central nucleus }\end{array}$ \\
Primary growth (PG) & Polyhedral and highly basophilic with a large nucleus, where several nucleoli can easily be observed \\
Cortical alveolar (CA) & Cortical alveoli and lipids appear in the cytoplasm \\
Primary vitellogenic (Vtg1) & Appearance of small granules of yolk around the nucleus \\
Secondary vitellogenic (Vtg2) & Larger yolk globules throughout the cytoplasm \\
Tertiary vitellogenic (Vtg3) & Large yolk globules fill the cytoplasm; oil droplets surround the nucleus \\
Germinal vesicle migration (GVM) & Germinal vesicle migrates to animal pole \\
Germinal vesicle breakdown (GVBD) & Germinal vesicle membrane breaks down; yolk globules become hydrated \\
Hydrated (HO) & Homogeneous appearance; oocytes ready to be released \\
Atretic (AO) & Irregular form of the oocyte and the fragmentation or disappearance of the nucleus \\
Post-ovulatory Follicle (POF)o & Formed of follicular cells, basement membrane and theca. POFs are irregular in form and remain in the ovary until \\
& subsequent reabsorption \\
\hline
\end{tabular}

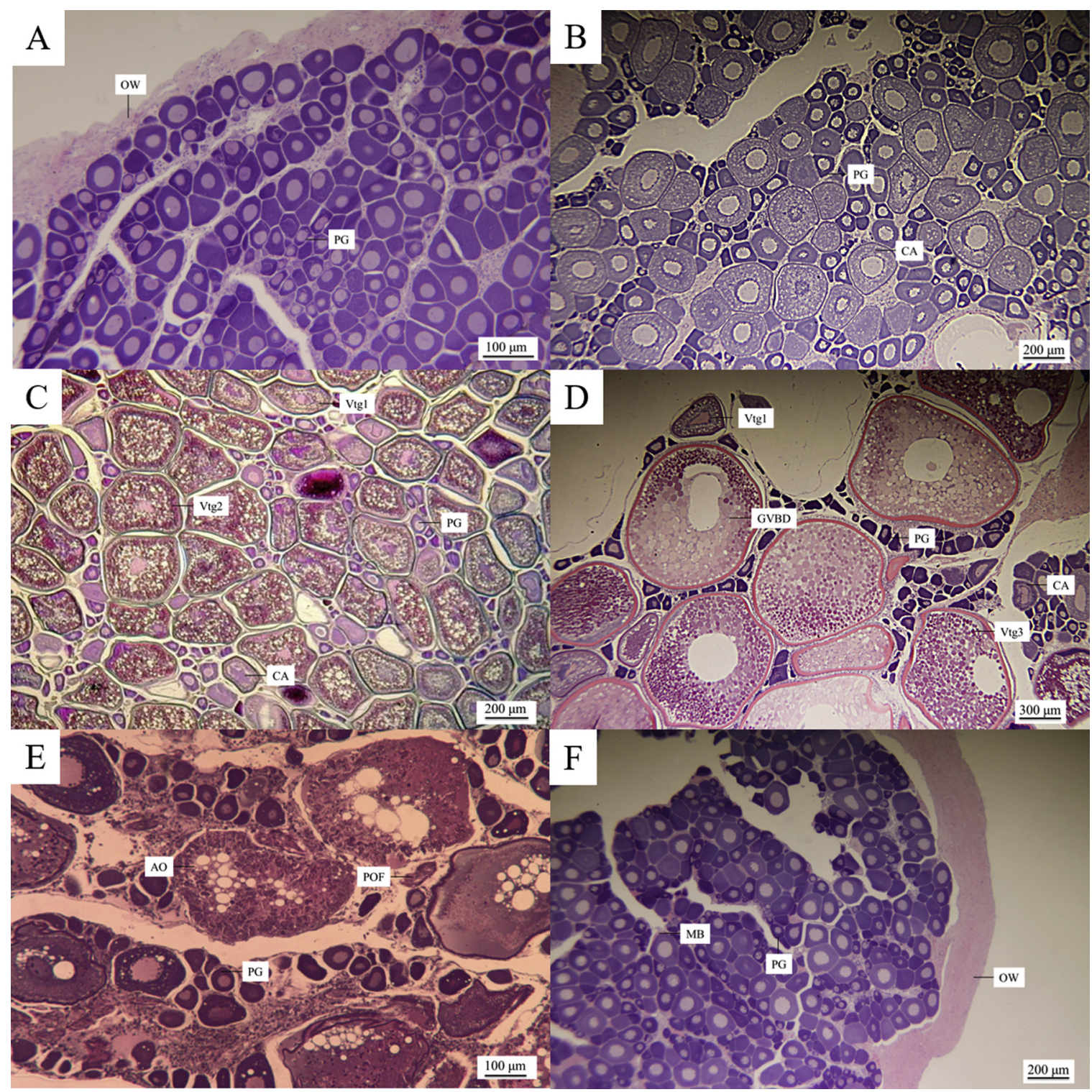

Fig. 2. Histological sections of Merluccius merluccius ovaries at different maturity stages. A) immature = virgin ovary, stage 1 and virgin developing, stage 2a; B) recovering ovary, stage $2 \mathrm{~b}$; C) maturing ovary, stage 2c; D) mature/spawner ovary, stage 3; E) spent ovary, stage 4a; F) resting ovary, stage 4b. PG, primary growth oocyte; CA, cortical alveolar oocyte; Vtg1, primary vitellogenic oocyte; Vtg2, secondary vitellogenic oocyte; Vtg3, tertiary vitellogenic oocyte; GVBD, germinal vesicle breakdown; POF, post-ovulatory follicle; AO, atretic oocyte; OW, ovarian wall; MB, muscle bundle. 
Table 4

Summary of oocyte development in European hake ovaries described for each macroscopic maturity stage in the MEDITS scale (GVM, Germinal vesicle Migration, GVBD, Germinal Vesicle breakdown; HO, Hydrated Oocytes).

\begin{tabular}{lll}
\hline Stage & Maturition state & Microscopic characteristics \\
\hline 1 & IMMATURE-VIRGIN & Only OO and PG through the perinuclear stage are present. The ovarian wall is thin and little space between oocytes are observed. \\
2a & VIRGIN-DEVELOPING & \\
2b & RECOVERING & Only PG and CA oocytes are visible. \\
2c & MATURING & PG, CA, Vtg1 and Vtg2 oocytes are observed. No evidence of POFs. Some atresia can be present. \\
3 & MATURE/SPAWNER & All stages present: PG, CA, Vtg1, Vtg2, Vtg3 oocytes and/or oocytes undergoing hydration (GVM, GVBD, HO). If spawning is already started, \\
& POFs are observed. Atresia (AO) of vitellogenic and/or hydrated oocytes may be present. \\
4a & SPENT & Atresia of vitellogenic oocytes and POFs can be visible. PG and CA present. \\
4b & RESTING & Only OO and PG oocytes (sometimes with circumnuclear oil droplets) are observed. The ovarian wall is thicker and there is more space, \\
& & interstitial tissue and capillaries around PG oocytes than those observed at the immature stage.
\end{tabular}

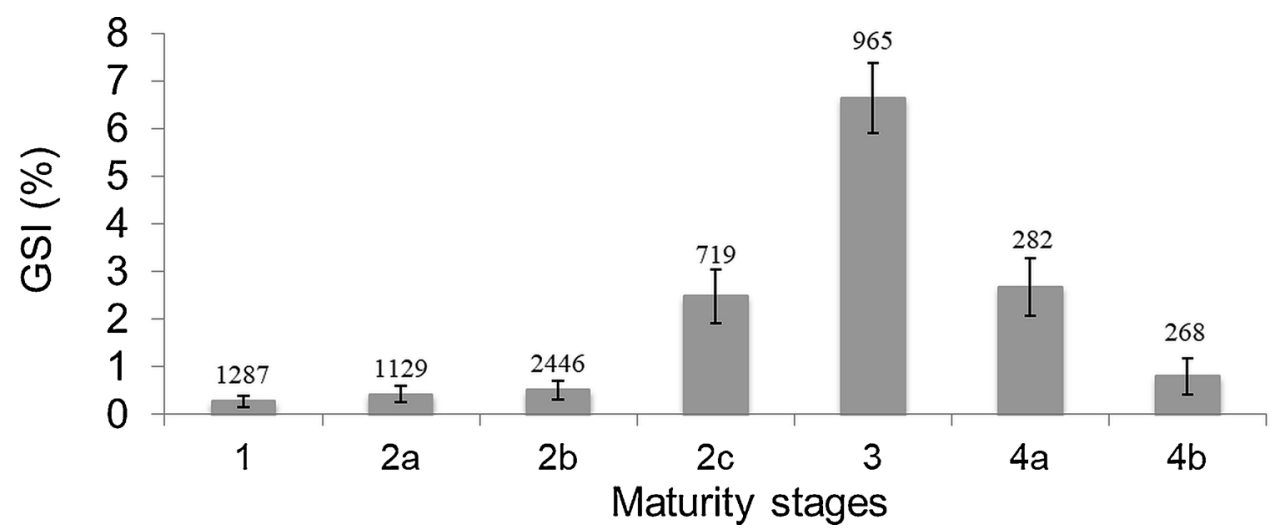

Fig. 3. Merluccius merluccius mean gonadosomatic index (GSI) by maturity stage. The bars indicate standard errors. The numbers above the bars indicate the sample size: 1 , immature - virgin; 2a, virgin - developing; 2b, recovering; 2c, maturing; 3, mature/spawner; 4a, spent; 4b, resting.

\section{Results}

\subsection{Oocyte development}

\subsubsection{Histological staging}

The histological screening of each macroscopic maturity stage was performed (Table 3 and Fig. 2). The detailed characteristics of oogenesis are listed in Table 3. An asynchronous maturing pattern was evident.

Immature stages (Stage 1 and 2a) are characterised mainly by oogonia (OO) and small primary growth oocytes (PG). As females move into the gonadotropin-dependent adult phase (stage $2 \mathrm{~b}$ ), ovaries can be histologically discerned by the appearance of cortical alveolar oocytes (CA), which are larger than PGs. Previtellogenic oocytes were present in all stages, and they represented the dominant component in the recovering females (2b stage). Vitellogenesis occurs when ovary maturation begins. Ovarian maturation consists of a series of events that begin when fully yolked (post-vitellogenic) oocytes are encapsulated in their follicles and culminate in the ovulation of fertilisable eggs (Reading et al., 2017). Primary (Vtg1) and secondary (Vtg2) vitellogenic oocytes were found together with PGs and CAs in stage 2c. The histological analysis was conducted to determine the minimum oocyte size at the beginning and the end of vitellogenesis: $150 \mu \mathrm{m}$ and $650 \mu \mathrm{m}$, respectively. Divided into three phases, vitellogenesis develops into the nuclear migration stage (GVM) up to the complete maturation-hydration phase, which are easily recognised in the translucent appearance of oocytes at a maximum size of $1150 \mu \mathrm{m}$. The progression to the maturespawner phase (stage 3) was characterised by the tertiary vitellogenic oocytes (Vtg3) and the hydrated oocytes (HO) at different maturation. At this stage, it was possible to check for the presence of post-ovulatory follicles (POF) of different sizes related to their cellular degeneration and reabsorption. These indicated previous spawning activity. As the oocyte maturation process ends, the females move into the spent stage (stage 4a), which is recognisable mainly by the presence of atretic oocytes and POFs. After the spent stage, the individuals move into the regenerating phase (stage $4 \mathrm{~b}$ ), which is characterised histologically by the appearance of $\mathrm{OO}$ and PG oocytes. At this stage, circumnuclear oil droplets can be seen in the PG oocytes (Table 4).

The analysis of GSI by maturity stage (Fig. 3) showed a gradual increase from the immature/virgin stage $(0.28 \pm 0.004$, mean \pm S.E. $)$ to the mature/spawner stage $(6.63 \pm 0.73)$. Subsequently, the GSI decreased in the spent and resting maturity stages in accordance with the ovary growth process.

The non-parametric Kruskal-Wallis test showed significant differences in the GSI values among the seven maturity stages $(p<0.05)$. In particular, significant differences were detected among all maturity stages $(\mathrm{p}<0.05)$, except the maturing and spent stages.

\subsubsection{Oocyte size-frequency distribution}

The oocyte diameter frequency distributions (ODF) of the different maturity stages are shown in Fig. 4. Immature and recovering ovaries (stage 1, 2a and 2b) showed an oocyte unimodal distribution with a peak at $30 \mu \mathrm{m}$, which corresponded to the primary growth oocyte population. The difference in ODF between the juvenile (1 virgin, and 2a virgin developing) and adult ( $2 \mathrm{~b}$ recovering) was due to the presence in the recovering stage of the CA oocytes, which were larger in size than the oocytes in the previous developmental stages (Fig. 4). In the maturing stage (2c), the ovaries showed a continuous and multimodal ODF with different modes corresponding to $200 \mu \mathrm{m}$ (14.1\%), $300 \mu \mathrm{m}(20 \%)$, $400 \mu \mathrm{m}(17.5 \%)$. The presence of several modes corresponding to spawning batches increased even more in the mature/spawner ovaries (stage 3). Three other modes of $700 \mu \mathrm{m}, 800 \mu \mathrm{m}$ and $900 \mu \mathrm{m}$ were observed, which coincided with advanced vitellogenesis (Vtg3), germinal vesicle (nuclear) migration (GVM) and germinal vesicle breakdown (GVBD, early hydrated oocytes). Moreover, a gap was observed between the early hydrated oocytes $(1050 \mu \mathrm{m})$ and the fully hydrated oocytes $(\geq 1150 \mu \mathrm{m})$. This gap could be related to the low sample sizes at the upper end of the oocytes size distribution. The spent ovaries 

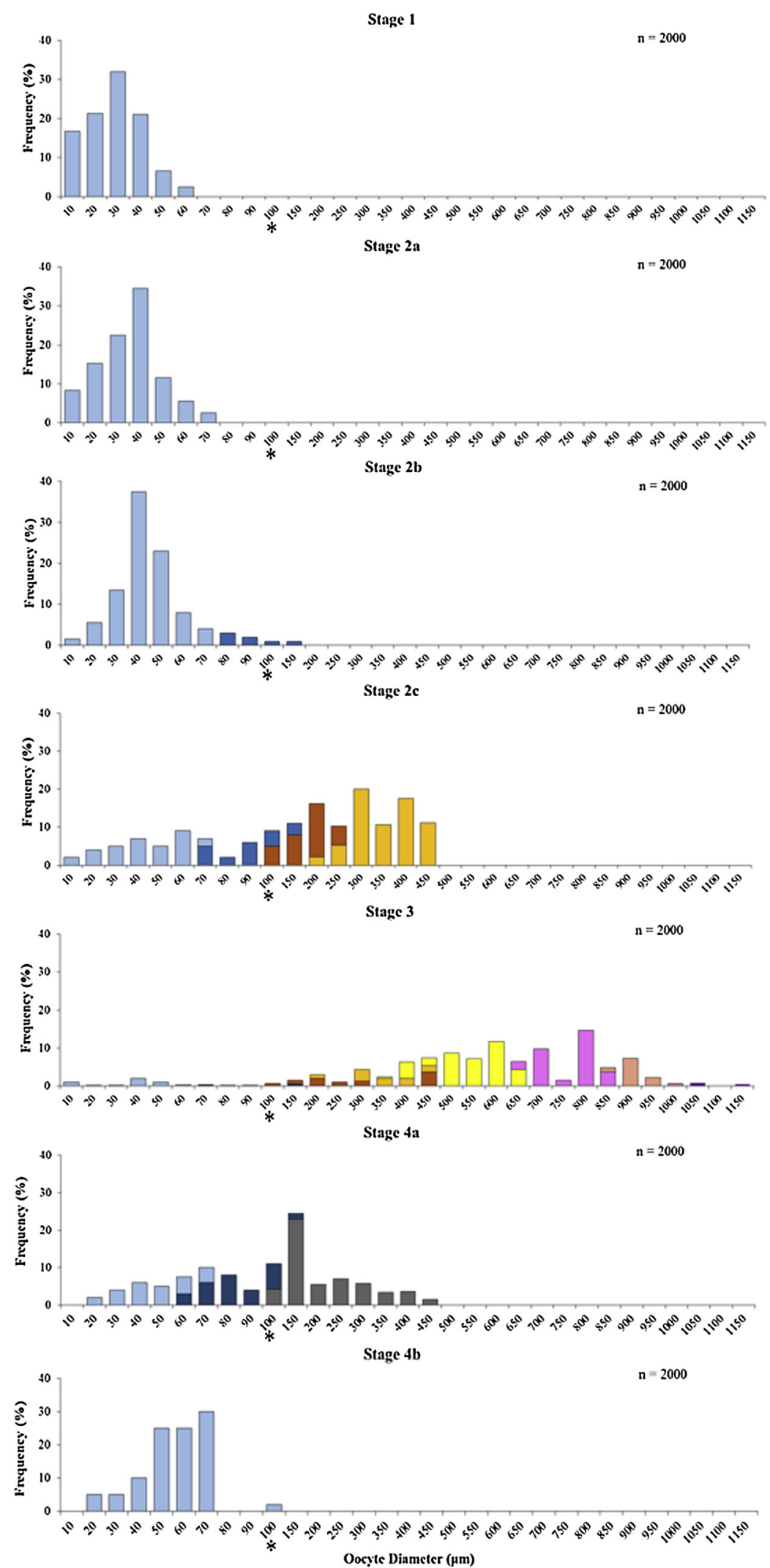

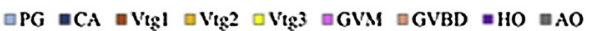

Fig. 4. Oocyte diameter frequency distributions (ODF) in M. merluccius in each ovarian maturity stage: 1 immature-virgin (A); 2a virgin - developing (B); 2b recovering (C); 2c maturing (D); 3 mature/spawner (E); 4a spent (F); $4 \mathrm{~b}$ resting (G). In each gonad, $n=2000$ measures were taken. The asterisk $(*)$ indicate the change of length class in the graph. PG, primary growth oocyte; CA, cortical alveolar oocyte; Vtg1, primary vitellogenic oocyte; Vtg2, secondary vitellogenic oocyte; Vtg3, tertiary vitellogenic oocyte; GVBD, germinal vesicle breakdown; HO hydrated oocytes; AO, atretic oocyte. 

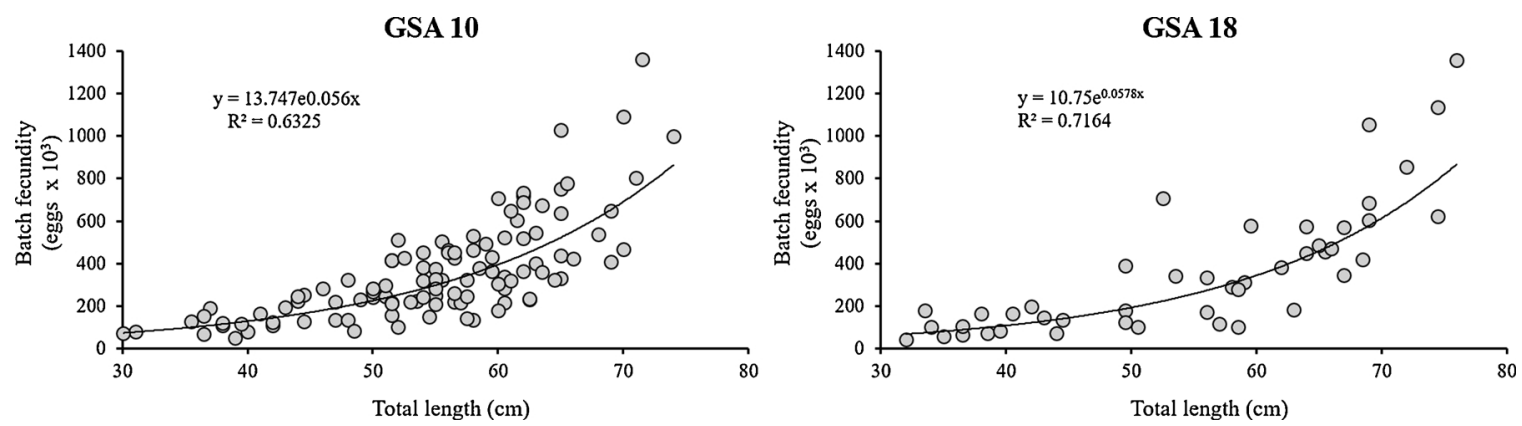

Fig. 5. Relationship between batch fecundity (eggs x $10^{3}$ ) and total length (cm) in (A) the Central Southern Tyrrhenian Sea (GSA 10) and B) Southern Adriatic Sea (GSA 18).

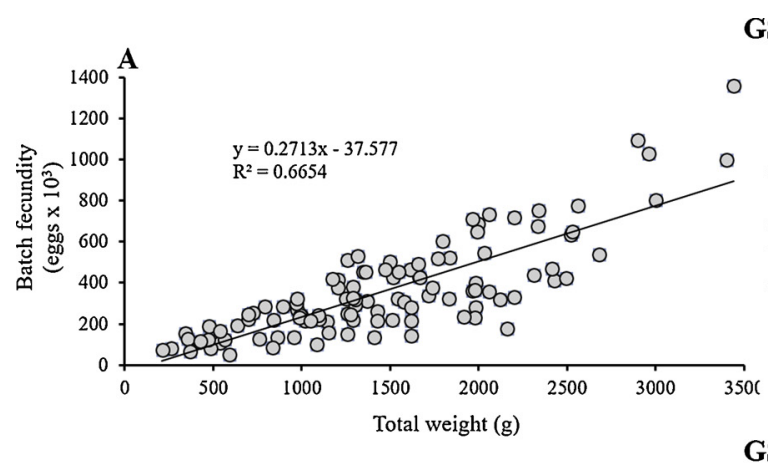

GSA 10
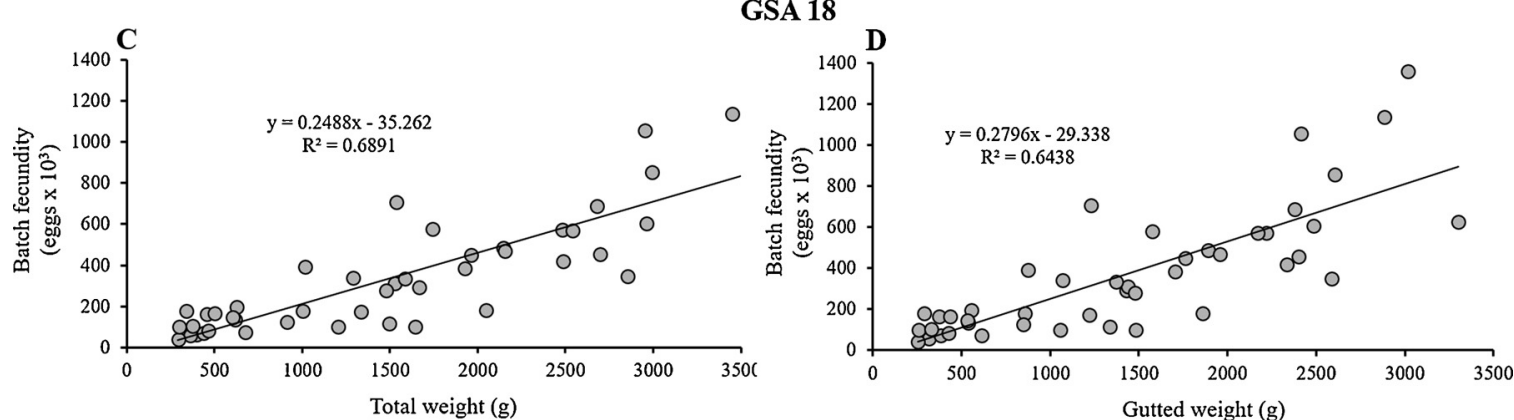

Fig. 6. Relationships between batch fecundity (eggs $\times 10^{3}$ ) and total weight and gutted weight for both A-B) GSA 10 (Central Southern Tyrrhenian Sea) and (C-D) GSA 18 (Southern Adriatic Sea).

showed a high percentage of atretic (degenerating/resorbing) oocytes and a portion of small oocytes (mainly PG), whereas the resting phase was characterised by the unimodal distribution of PG oocytes.

\subsection{Batch fecundity}

In GSA10, batch fecundity varied from 49,243 (39 cm TL) to $1,359,671$ mature oocytes $(71.5 \mathrm{~cm} \mathrm{TL})$, while in GSA18, it ranged from 41,155 (32 cm TL) to 1,356,494 (76 cm TL). The BF-TL relationship was described by a positive exponential curve ( $\mathrm{p}>0.05$ ) (Fig. 5A, B). There was no significant difference between these two BF-TL curves $\left(\mathrm{F}_{\text {critical }}=2.67>\mathrm{F}_{\text {observed }}=0.27 ; \mathrm{p}>0.05\right)$. BF was significantly positively correlated with both GW $(\mathrm{p}<0.05)$ and TW $(\mathrm{p}<0.05)$ (Fig. 6A-D). There was no statistically significant difference in the slope comparison between $\mathrm{BF}$ and $\mathrm{GW}$ for the two areas $\left(\mathrm{F}_{\text {critical }}=3.904>\mathrm{F}_{\text {observed }}=1.13 ; \mathrm{p}>0.05\right)$. The mean batch fecundity was 360,687 eggs/fish ( \pm SD 234782 ) and 361,311 eggs/fish ( \pm SD 306028), respectively, for GSA10 and GSA18. The relative batch fecundity was $281.6{\text { eggs } g^{-1}}^{(} \pm$SD 101.5) for the GSA10 and 262.2 eggs $g^{-1}( \pm$ SD 124.7) in GSA18.

\subsection{Spawning cycle}

The percentages of $M$. merluccius females in different maturity stages that were observed monthly indicated that specimens from maturing to resting were present throughout the year in all areas (Fig. 7). Spawning peaks were evident for all GSAs although they showed slight variations. The reproductive activity in all areas was concentrated in winter (December-March) with spawning peaks in December, January and February. In all GSAs, maturing and mature/spawner females were observed throughout the year with the highest occurrence between December and February. Outside this period for GSA11, the percentage of mature/spawning females was consistent but relatively low (about $10 \%$ ), unlike in other GSAs where further spawning activity was detected from late summer to early autumn (i.e. August-October). A large proportion of recovering females was always present in all GSAs.

The monthly pattern in maturity stages was mirrored by the monthly variation in GSI and HSI in all study areas (Fig. 8). In GSA10, GSI was highest from January toMarch $(4.46 \pm 0.33-3.94 \pm 0.51)$, followed by another peak in the summer months (August, $2.65 \pm 0.22-$ September $2.69 \pm 0.31$ ). In GSA18 and GSA19, a winter (December-January, $3.25 \pm 0.19-3.95 \pm 0.36$; December-January, $3.18 \pm 0.50-2.58 \pm 0.41$, respectively) and a summer peak (August-September, $2.85 \pm 0.24-2.93 \pm 0.18$; August-September, $2.47 \pm 0.52-2.62 \pm 0.26$, respectively) were identified. In GSA11, the highest GSI values were observed in winter (December-February) with a peak in January $(2.88 \pm 0.95)$.

The monthly trend of HSI in GSA10 showed the highest values in 

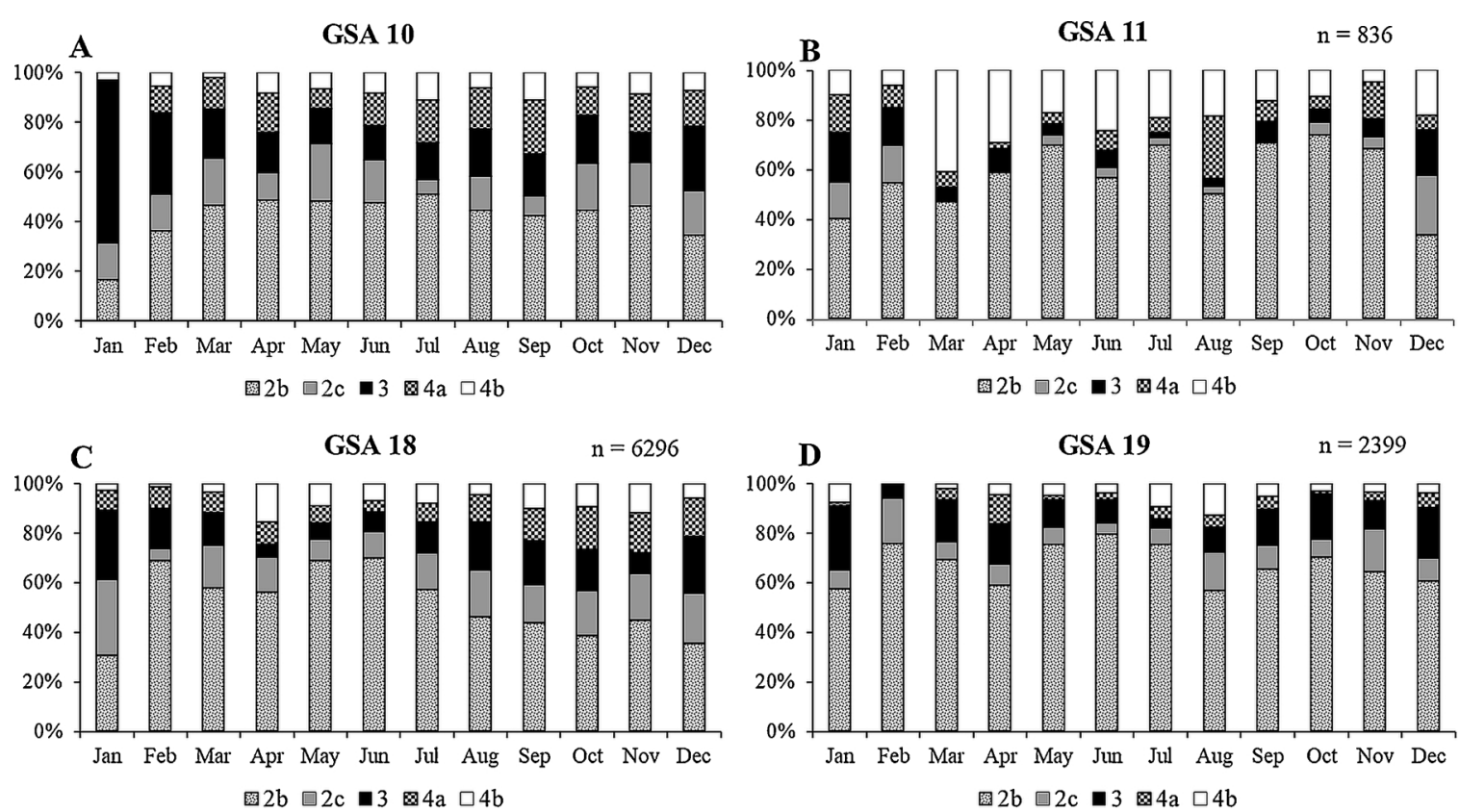

Fig. 7. Monthly percentages of M. merluccius female maturity stages in A) the Central Southern Tyrrhenian Sea (GSA 10), B) Sardinian seas (GSA11), C) Southern Adriatic Sea (GSA 18) and D) Western Ionian Sea (GSA19) (maturity stage classification: 2b, recovering, 2c, maturing, 3, mature/spawner, 4a, spent and 4b, resting).

November and December, that is, before the spawning peaks, and the lowest value in April, that is, immediately after the winter spawning peak. In GSA11, the highest HSI value was observed during the summer months between June and August.

\subsection{Length at maturity}

The $\mathrm{L}_{50}$ values in different areas were estimated by pooling the data from all years together (Fig. 9). The lowest $L_{50}$ was observed for GSA11 ( $30.03 \mathrm{~cm} \mathrm{TL})$, followed by GSA18 $(31.95 \mathrm{~cm} \mathrm{TL})$. The highest $\mathrm{L}_{50}$ values were found in GSA10 (33.03 cm TL) and GSA19 (32.94 cm TL). Statistically significant differences were determined among the four geographical areas (Chen test, $\mathrm{p}<0.05$ ).

Concerning the temporal trends of $\mathrm{L}_{50}$ based on MEDITS data, the lowest and the highest $\mathrm{L}_{50}$ values estimated for females in GSA10, respectively, were in $2009(31.4 \pm 0.1 \mathrm{~cm}$, MR $2.1 \pm 0.1 \mathrm{~cm})$ and 2014 $(34 \pm 0.1 \mathrm{~cm}$ (MR $1.8 \pm 0.1 \mathrm{~cm})$. For GSA18, the smallest $\mathrm{L}_{50}$ was $30.8 \pm 0.2 \mathrm{~cm}$ (MR $2.2 \pm 0.2 \mathrm{~cm}$ ) in 2011, and the highest $\mathrm{L}_{50}$ was $33.1 \pm 0.1 \mathrm{~cm}$ (MR $3.2 \pm 0.1 \mathrm{~cm}$ ) in 2013. The $\mathrm{L}_{50}$ estimated in Sardinian females from 2007 to 2015 ranged between 29.1 ( \pm 0.05 ) and $31.4\left( \pm 0.12\right.$ ), whereas the lowest and the highest $L_{50}$ values estimated in GSA19, respectively, were $32.0 \pm 0.8 \mathrm{~cm}$ (MR $5.8 \pm 0.9 \mathrm{~cm})$ in 2010 and $37.8 \pm 0.5 \mathrm{~cm}(\mathrm{MR} 2.2 \pm 0.7 \mathrm{~cm})$ in 2013. The Spearman test did not identify statistically significant trends among the years $(\mathrm{p}>0.1)$.

\section{Discussion}

In fishery science, a core information requirement is the identification of the stock spawning component. The evaluation of individual sexual maturity has traditionally been carried out by macroscopic assignment based on the visual inspection of gonads. Although this method is rapid and cheap (Tomkiewicz et al., 2003), it is not always accurate (Costa, 2009; Vitale et al., 2006). The bias in macroscopic maturity analysis is usually linked with inconsistent descriptions of the maturity stages. Because of the asynchronous oocyte development in $M$. merluccius (Hunter et al., 1985; Murua and Motos, 2006), the presence of particular structures, such as post-ovulatory follicles and atretic oocytes, cannot be detected by visual inspection (Hunter and Macewicz,
1985; Murua et al., 2003). The main misclassification occurs between the virgin-developing and regenerating stages and/or the spawning and post-spawning stages (ICES, 2007, 2008). The macroscopic identification of some stages remains very difficult, particularly in the virgin developing and recovering stages as well as in the resting stage. Microscopic evaluation using histological analysis enables a more precise classification of gonad development than the naked eye can achieve, allowing not only reliable maturity classifications but also correct determination of the spawning period (Vitale et al., 2005) and accurate estimates of length at maturity (Hunter and Macewicz, 1985; Murua et al., 2003; Vitale et al., 2006; Ferreri et al., 2009). Moreover, investigating fish resource allocation by collecting data on gonad and liver weight has proven useful to unravel the uncertainties in maturity visual staging (Vitale et al., 2006). The analysis of the annual variation in GSI and HSI could help to identify the wrong assignments of maturity stages in some species (ICES, 2007).

In the present study, the macroscopic maturity key commonly used for female hake was validated using histological analyses. This macroscopic scale is largely used in the Mediterranean context and is endorsed by the MEDITS Working Group (AAVV, 2017). Moreover, the GSI analysis of maturity stages has indicated that the relative size of the gonad in the European hake differs among maturity stages, especially between immature and adult specimens. This confirms that the relative ovary size can be used as an objective characteristic in the macroscopic analysis of the gonad.

Histological observations and the oocyte diameter frequency distribution (ODF) in mature-spawner females confirmed that the European hake is a batch spawner with asynchronous ovary organisation (Murua and Saborido-Rey, 2003). This result is in alignment with those of other previous studies on the Mediterranean and Atlantic areas (e.g. Al-Absawy, 2010; Murua et al., 2006, 1998; Murua and Motos, 2006; Recasens et al., 2008). The ODF showed a polymodal pattern in both maturing and mature/spawner females with continuously size range from PG to Vtg3 and there is no large hiatus between maturity classes of oocytes except that between the hydrated and tertiary vitellogenic oocytes. In addition, in the recovery stage, the observation of a stock of early previtellogenic oocytes (CA oocytes) is in accordance with a continuous, indeterminate fecundity strategy in hake (Korta et al., 2010). Every mode corresponded to different vitellogenic stages 

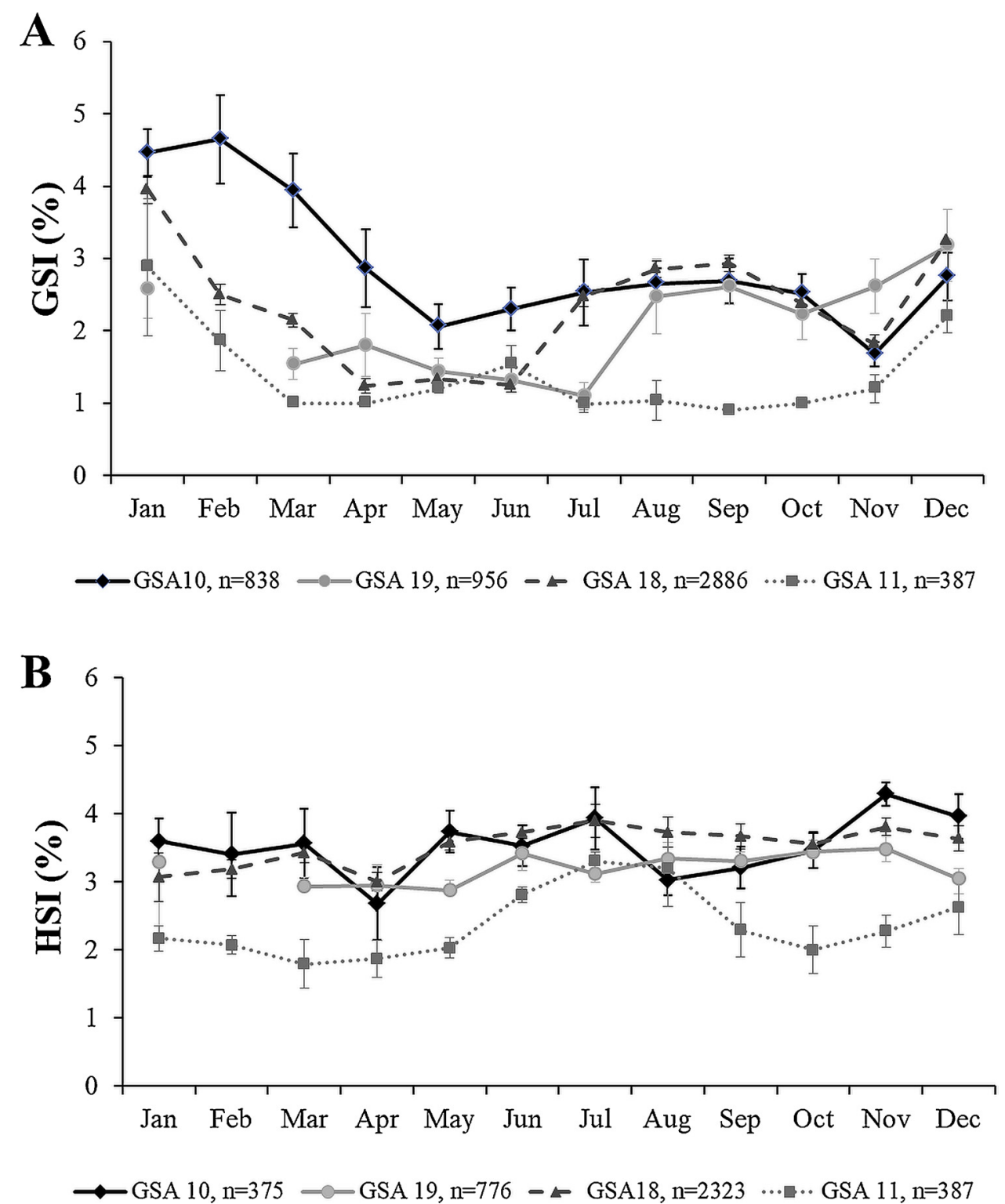

Fig. 8. Monthly evolution of A) Gonadosomatic index (GSI, mean \pm S.E.) and B) Hepatosomatic index (HSI, mean \pm S.E.) in the Central Southern Tyrrhenian Sea (GSA 10), Southern Adriatic Sea (GSA 18), Western Ionian Sea (GSA19) and Sardinian seas (GSA 11).

(Murua and Motos, 2006; Al-Absawy, 2010; El Habouz et al., 2011), which suggests a continuous maturation pattern of oocytes and egg spawning in successive batches (Murua et al., 2006; Murua and Motos, 2006; Recasens et al., 2008; Al-Absawy, 2010; El Habouz et al., 2011).

The values of fecundity were reported for the first time for Central Tyrrhenian and Southern Adriatic Sea in this study. The relative batch fecundity estimates reported in this study (281.6 eggs g ${ }^{-1}$ GSA10 and 262.2 eggs $^{-1}$ GSA18) seemed comparable with the previous estimates reported for the eastern central Atlantic (228.33 eggs $\mathrm{g}^{-1}$ ) (El Habouz et al., 2011). However, they were higher than those estimated in Catalan waters (204.29 eggs ${ }^{-1}$ ), the North Tyrrhenian $\left(202.35\right.$ eggs g $^{-1}$ ) (Recasens et al., 2008), the Gulf of Lion (127 eggs $\mathrm{g}^{-1}$ ) (Ferrer-Maza et al., 2014) and the Bay of Biscay (165-123 eggs $\mathrm{g}^{-1}$ ) (Murua et al., $1998,2006)$. Similar to the relative batch fecundity, the mean batch fecundity estimates (360,687 eggs per female GSA 10 and 361,311 eggs per female GSA 18) were higher than those reported for the Moroccan Atlantic area (299,872 eggs per female) (El Habouz et al., 2011), the Bay of Biscay (220,636 eggs per female) (Murua et al., 2006), the Gulf of Lion (137,077 eggs per female) (Ferrer-Maza et al., 2014), the Catalan Sea $(126,035$ per female), and the North Tyrrhenian Sea $(185,821$ eggs per female) (Recasens et al., 2008).

In accordance with previous data on the Atlantic and Mediterranean areas (i.e. Recasens et al., 2008; Domínguez-Petit et al., 2010; El Habouz et al., 2011), the estimates of batch fecundity found in this study increased proportionally with size and weight, which was probably due to the greater capacity for obtaining the energy of the bigger females (Domínguez-Petit et al., 2010; Ferrer-Maza et al., 2014). In addition, although few data are available in the literature, the fecundity data showed a positive North-South trend. However, this aspect needs to be further investigated by taking into account the seasonal and annual variability (Murua et al., 2006; Recasens et al., 2008; Ferrer-Maza et al., 2014).

The results of this study indicated that the Mediterranean hake has a protracted spawning season in Italian waters that incorporates the whole year. This is consistent with the results obtained in several Mediterranean areas (Table 5). The spawning peak occurred in winter for all four years, with another short peak in summer for GSA10, GSA18 and GSA19. The period and the length of the spawning period may be influenced by many intrinsic (i.e. life stage, condition and parasitism) and extrinsic (i.e. temperature, current, prey concentration and 

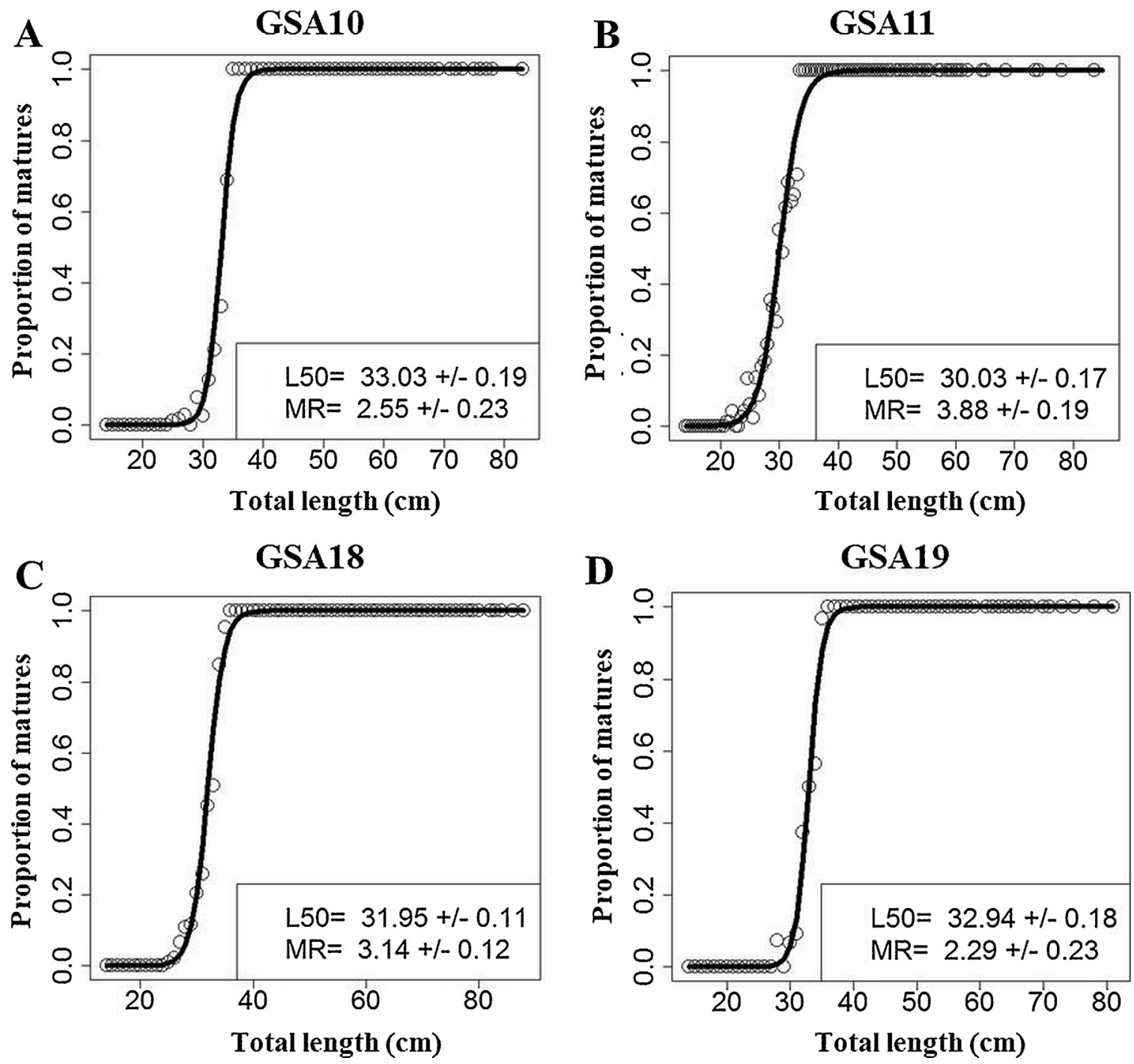

Fig. 9. Merluccius merluccius maturity ogives in A) GSA 10, B) GSA 11, C) GSA 18, D) GSA 19 (years 2014-2015). The maturity range (MR) and L50 are also reported.

Table 5

Reproductive and spawning period of Merluccius merluccius females in different Mediterranean areas Bennoui et al. (1998), Reňones et al. (1995), Recasens et al. (2008), Belcari et al. (2006), Biagi et al. (1995), Khoufi et al. (2014), Arneri and Morales-Nin (2000), Dulčić et al. (2005), Ungaro et al. (1993), Soykan et al. (2015) and Al-Absawy (2010).

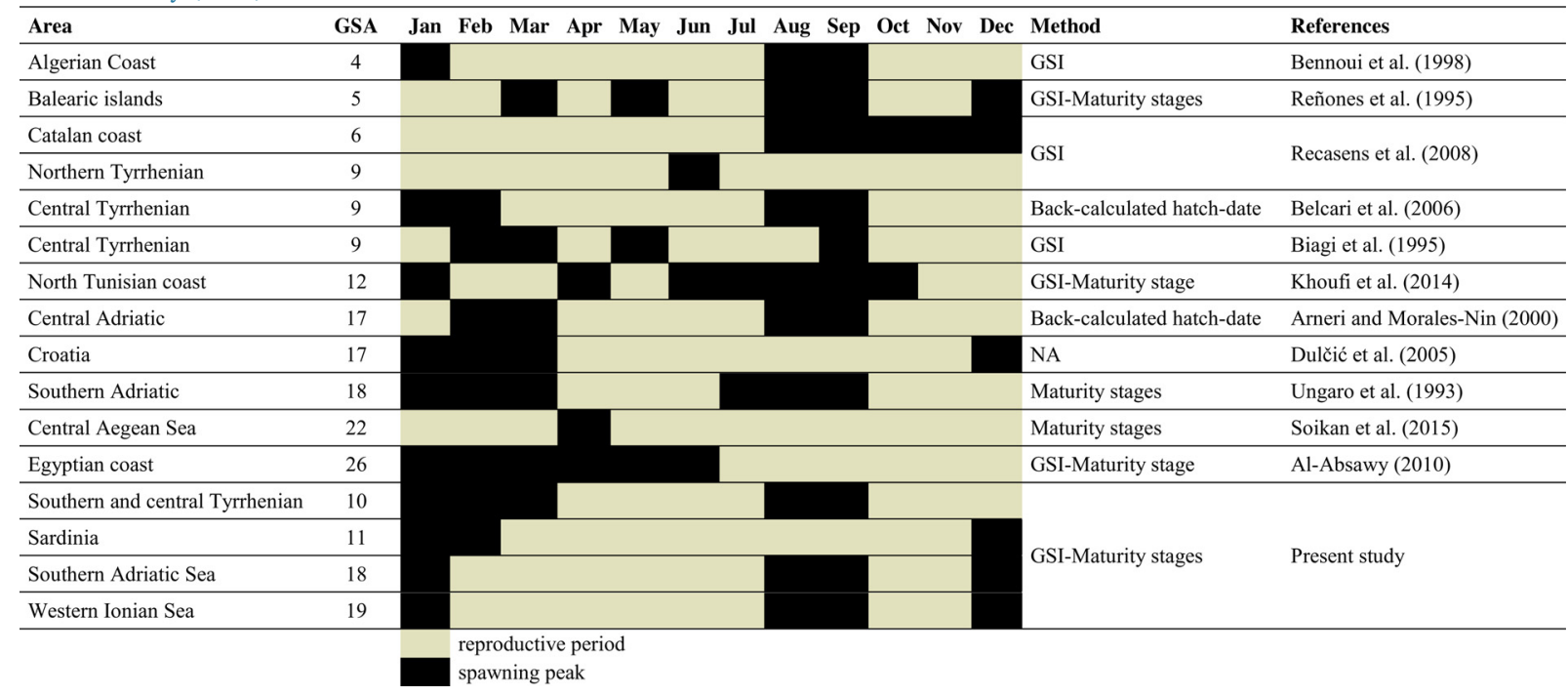


Table 6

$\mathrm{L}_{50}$ values of Merluccius merluccius females for different Mediterranean areas.

\begin{tabular}{llll}
\hline Area & GSA & $\begin{array}{l}\text { L }_{50} \text { (TL, } \\
\text { cm) }\end{array}$ & References \\
\hline Algerian coast & 4 & 30.6 & Bennoui et al. (1998) \\
Balearic Sea & 5 & 36.3 & Reňones et al. (1995) \\
Majorca Island & 5 & 36.3 & Oliver (1991) \\
Catalan coast & 6 & 39.0 & Sànchez and Martìn (1985) \\
Catalan coast & 6 & 35.8 & Recasens et al. (2008) \\
Gulf of Lion & 7 & 43.0 & Aldebert and Carriès \\
& & & (1989) \\
Gulf of Lion & 7 & 42.0 & Campillo (1992) \\
Gulf of Lion & 7 & 38.0 & Recasens et al. (1998) \\
Northern Tyrrhenian & 9 & 35.1 & Recasens et al. (2008) \\
Northern Tyrrhenian Sea & 9 & 42.5 & Biagi et al. (1995) \\
Tunisian coast & $12-13-14$ & 29.0 & MedSudMed (2008) \\
North Tunisian coast & 12 & 28.79 & Khoufi et al. (2014) \\
Strait of Sicily & 16 & 33.5 & Ragonese et al. (2004) \\
Northern-Central Adriatic & 17 & 31.3 & Alegria Hernandez and \\
$\quad$ Sea & & & Jukic (1992) \\
Greece coast & $20-22-23$ & 36.0 & Stergiou et al. (1997) \\
Central Aegean Sea & 22 & 21.5 & Soykan et al. (2015) \\
Egyptian coast & 26 & 32.5 & Al-Absawy (2010) \\
Southern-Central & 10 & 33.03 & Present study \\
$\quad$ Tyrrhenian Sea & & & \\
Sardinia & 11 & 30.03 & Present study \\
Southern Adriatic Sea & 18 & 31.95 & Present study \\
Western Ionian Sea & 19 & 32.95 & Present study \\
\hline & & & \\
\hline
\end{tabular}

pollution) factors (Recasens et al., 2008; Bodiguel et al., 2009; Domínguez-Petit et al., 2010; Mehault et al., 2010; Gucu and Bingel, 2011; Ferrer-Maza et al., 2014). In Catalan waters, for instance, the phenomenon of surface dense water formation and later cascading events with high current speed (about $80 \mathrm{~cm} \mathrm{~s}^{-1}$ ) is the likely cause of the unfavourable conditions for hake spawning in the winter months (Recasens et al., 2008). European hake reproduction depends mainly on energy intake during spawning season (Domínguez-Petit et al., 2010) and the density and quality of prey (Harmelin Vivien et al., 2012; Ferrer-Maza et al., 2014).

The presence in several Mediterranean areas of two reproduction peaks in winter and late summer could be explained by the corresponding biomass peaks in anchovy (in winter) and sardine (in late summer) (Patti et al., 2004; Giannoulaki et al., 2008; Martín et al., 2008; Tugores et al., 2011; Quattrocchi and Maynou, 2017). These species are the preferred preys of M. merluccius spawner females in Mediterranean Sea (Carpentieri et al., 2005).

The estimation of spawning frequency in hake (i.e. number of spawning events within a spawning period for an individual, sensu Lowerre-Barbieri et al., 2011) remains unknown, especially in the Mediterranean area (Murua and Motos, 2006). In other gadoids, such as cod, haddock, whiting, Norway pout and pouting, the period of egg production by individual females has been estimated at two months (Hislop et al., 1978; Kjesbu, 1989; Alonso-Fernández et al., 2008). However, for the European hake, the only available information on spawning frequency at the population level (at intervals between 6 and 12 days during the spawning season) is for the Bay of Biscay (Murua and Motos, 2006).

The seasonal patterns of GSI and HSI in GSA 11 confirmed that hake is a capital breeder (Ferrer-Maza et al., 2014), implying that the energy invested in reproduction is derived from energy that is stored during the summer and autumn months. The liver is the major organ of lipid storage in this species (Lloret et al., 2008), and gonads develop to the detriment of the accumulated lipidic energy in the liver (Ferrer-Maza et al., 2014). This previous finding supports the complementary monthly trend observed in this study according to two indices of resource allocation. Because the GSI is an index of gonadal maturity, a higher value shows that the gonads are developing/maturing, whereas a lower value indicates the end of the spawning period. The HSI is a proxy for the energy reserves available for reproduction and gonad maturation. When the yolk (vitellus) is accumulated, the HSI decreases rapidly, showing the energy flow from the liver to the gonads. Thus, during the fish life cycle, the HSI peak usually precedes the GSI peak in a seasonal pattern as it was observed in the GSA11.

In the other GSAs (10, 18 and 19) analysed in present study no clear complementary pattern between GSI and HIS was identified, probably due to the presence of the reproductive peak in the summer. FerrerMaza et al. (2014) argued that the Mediterranean hake is capable to change its reproductive strategy and become an income breeder (the energy required for reproductive effort comes from concurrent feeding) during summer. The reason for this change could be the higher prey availability during the summer months in the Mediterranean (Bozzano et al., 1997; Martín et al., 2008; Quattrocchi and Maynou, 2017). These differences could demonstrate that hake is a plastic species with a highly adaptable breeding strategy according to the biotic and nonbiotic factors in each geographical area (Ferrer-Maza et al., 2014). However, the monthly trend of HSI for the GSA 10, 18 and 19 are not so well defined to confirm the change of reproductive strategy. The observed pattern could also be due to the individual variability.

With regard to size at maturity $\left(\mathrm{L}_{50}\right.$; Table 6$)$, no previous estimates are reported in the literature regarding the Southern and Central Tyrrhenian Sea, the Sardinian seas, the Southern Adriatic Sea and the Western Ionian Sea. The estimates are comparable with the $\mathrm{L}_{50}$ reported in the Catalan Sea, the North Tyrrhenian Sea, and the Algerian and Egyptian coasts (Table 6). In general, the oldest $L_{50}$ estimates are higher. These differences could be explained by phenotypic responses to some environmental variations or by the evolutionary consequences of selective pressures, such as fishing effort (Barot et al., 2004), as well as by the different estimation and sampling methods applied (ICES, 2008). The use of the MEDITS survey data, which is standardised in terms of maturity scale (since 2007) and sampling scheme (AAVV, 2017), allowed us to detect the existence of a trend in $\mathrm{L}_{50}$.

The outcomes of the present study clarify some aspects of the reproductive biology of $M$. merluccius in the Western and Central Mediterranean Basin. Moreover, for the first time, some important reproductive parameters (i.e., length at maturity, fecundity, reproductive period) were estimated, providing an essential ground for stock assessment and ultimately for fishery management. The outdated knowledge of the reproductive biology of this species in the studied areas has often been an impediment to using stock-assessment models, particularly analytical models, which require maturity parameters as fundamental input data. The accuracy of the maturity analysis relies on validated maturity scales (ICES, 2008, 2014) mainly for species with indeterminate fecundity, such as the European hake. Therefore, the histological validation of the MEDITS maturity scale is an important contribution to better understanding the reproductive strategy of this important commercial resource.

\section{Conclusion}

One of the main contributions of this work is the validation of the MEDITS macroscopic maturity scale for use in research on the European hake. Although macroscopic maturity analysis is the method that is most widely applied for estimating reproductive parameters, the bias linked to the use of this method could affect the results and therefore the evaluation of the reproductive capacity of the stocks and their status. Indeed, stock-assessment models require maturity parameters (e.g. fecundity and length at maturity and spawning cycle) as the main input data. In this study, the MEDITS maturity scale was validated for the European hake female population according to histological analysis, oocyte diameter frequency distributions (ODF) and the gonadosomatic index (GSI). The results of this study indicated that the Mediterranean hake has a protracted spawning season that continues almost all year round. A spawning peak occurs mainly in winter (GSA10, GSA11, GSA18 and GSA19), and a short peak occurs in summer (GSA10, GSA18 
and GSA19). For the HSI, the annual trend showed different reproductive strategies according to the season: capital breeding during the winter months and income breeding in the summer months. The results of the reproductive patterns and $\mathrm{L}_{50}$ are in accordance with the existing knowledge of this species in the Mediterranean Basin.

\section{Declaration of Competing Interest}

\section{None.}

\section{Acknowledgements}

The data used in this study were collected in the context of Data Collection Framework, supported by the Italian Ministry of Agriculture, Food and Forestry Policy (MiPAAF) and by the European Commission. The authors are grateful to the two anonymous reviewers for their careful reading of this manuscript. Their useful comments and suggestions allowed us to improve our scientific research.

\section{References}

AAVV, 2017. MEDITS-Handbook. Version N. 9.

Abella, J.A., Martín, P., Maynou, F., Recasens, L., 2013. Report of the scientific, technical and economic committee for fisheries (STECF). 2013 Assessment of Mediterranean Sea Stocks Part I (STECF 13-22). European Union. Publications Office.

Al-Absawy, M.A.E.-G., 2010. The reproductive biology and the histological and ultrastructural characteristics in ovaries of the female gadidae fish Merluccius Merluccius from the Egyptian Mediterranean water. Afr. J. Biotechnol. 9, 2544-2559.

Aldebert, Y., Carriès, C., 1989. L'exploitation du merlu dans le golfe du Lion. Bull. la Société Zool. Fr. 114, 15-20.

Alegria Hernandez, V., Jukic, S., 1992. Abundance dynamics of the hake (Merluccius Merluccius L.) from the middle Adriatic Sea. Bull. Inst. Océanogr. 151-161.

Alonso-Fernández, A., Domínguez-Petit, R., Bao, M., Rivas, C., Saborido-Rey, F., 2008 Spawning pattern and reproductive strategy of female pouting Trisopterus luscus (Gadidae) on the Galician shelf of north-western Spain. Aquat. Living Resour. 21 383-393.

Arneri, E., Morales-Nin, B., 2000. Aspects of early life history of European hake from the central Adriatic. J. Fish Biol. 56, 1368-1380.

Barot, S., Heino, M., O'Brien, L., Dieckmann, U., 2004. Estimation of reaction norm for age and size at maturity with missing first-time spawner data. Evol. Ecol. Res. 6, $659-678$.

Belcari, P., Ligas, A., Viva, C., 2006. Age determination and growth of juveniles of the European hake, Merluccius Merluccius (L., 1758), in the northern Tyrrhenian Sea (NW Mediterranean). Fish. Res. 78 (2-3), 211-217.

Bertrand, J.A., de Sola, L.G., Papaconstantinou, C., Relini, G., Souplet, A., 2002. The general specifications of the MEDITS surveys. Sci. Mar. 66, 9-17.

Beverton, R.J.H., Holt, S.J., 1957. On the dynamics of exploited fish populations. Fish. Investig. 19, 1-533.

Biagi, F., Cesarini, A., Sbrana, M., Viva, C., 1995. Reproductive biology and fecundity of Merluccius Merluccius (Linnaeus, 1758) in the northern Tyrrhenian Sea. Rapp. Comm. Int. Mer Médit. 34, 237.

Bodiguel, X., Loizeau, V., Le Guellec, A.-M., Roupsard, F., Philippon, X., Mellon-Duval, C., 2009. Influence of sex, maturity and reproduction on PCB and p, p'DDE concentrations and repartitions in the European hake (Merluccius Merluccius, L.) from the Gulf of Lions (NW Mediterranean). Sci. Total Environ. 408, 304-311.

Bennoui, A., Bouaziz, A., Djabali, F., Maurin, C., 1998. Reproduction du merlu Merluccius Merluccius (Linnaeus, 1758) dans la région de Bou-Ismaïl. In: In: Lleonart, J. (Ed.), Dynamique des populations marines. Zaragoza: CIHEAM 35. pp. 109-117.

Bozzano, A., Recasens, L., Sartor, P., 1997. Diet of the European hake Merluccius Merluccius (Pisces: Merlucciidae) in the western Mediterranean (Gulf of Lions). Sci. Mar. 61 (1), 1-8.

Brown-Peterson, N.J., Wyanski, D.M., Saborido-Rey, F., Macewicz, B.J., Lowerre-Barbieri, S.K., 2011. A standardized terminology for describing reproductive development in fishes. Mar. Coast. Fish. 3, 52-70.

Campillo, A., 1992. Les pêcheries françaises de Méditeranée: synthèse des connaissances. Institut Francais de Recherche pour l'Exploitation de la Mer, France, pp. 206.

Carbonara, P., Intini, S., Modugno, E., Maradonna, F., Spedicato, M.T., Lembo, G., Zupa, W., Carnevali, O., 2015. Reproductive biology characteristics of red mullet (Mullus barbatus L., 1758) in Southern Adriatic Sea and management implications. Aquat. Living Resour. 28, 21-31. https://doi.org/10.1051/alr/2015005.

Cardinale, M., Damalas, D., Osio, G.C., 2015a. Scientific, Technical and Economic Committee for Fisheries (STECF): Mediterranean Assessments Part 2 (STECF-15-06), Publications Office.

Cardinale, M., Damalas, D., Osio, G.C. (Eds.), 2015. Scientific, Technical and Economic Committee for Fisheries (STECF) - Mediterranean assessments part 1 (STECF-15-18). Publications Office of the European Union Luxembourg, EUR 27638 EN, JRC 98676, $410 \mathrm{pp}$.

Cardinale, M., Modin, J., 1999. Changes in size-at-maturity of Baltic cod (Gadus morhua) during a period of large variations in stock size and environmental conditions. Fish.
Res. 41, 285-295.

Cardinale, M., Rätz, H.-J., Cheilari, A., Martín, P., Maynou, F., 2011. Scientific, Technical and Economic Committee for Fisheries (STECF). Assessment of Mediterranean StocksPart II. European Union. Publications Office.

Carpentieri, P., Colloca, F., Cardinale, M., Belluscio, A., Ardizzone, G.D., 2005. Feeding habits of European hake (Merluccius Merluccius) in the central Mediterranean Sea. Fish. Bull. 103, 411-416.

Cerri, P.S., Sasso-Cerri, E., 2003. Staining methods applied to glycol methacrylate embedded tissue sections. Micron 34, 365-372.

Chen, Y., Jackson, D.A., Harvey, H.H., 1992. A comparison of von bertalanffy and polynomial functions in modelling Fish growth data. Can. J. Fish. Aquat. Sci. 49, 1228-1235. https://doi.org/10.1139/f92-138.

Costa, A.M., 2009. Macroscopic vs. microscopic identification of the maturity stages of female horse mackerel. ICES J. Mar. Sci. 66, 509-516.

Domínguez-Petit, R., Saborido-Rey, F., Medina, I., 2010. Changes of proximate compo sition, energy storage and condition of European hake (Merluccius Merluccius, L. 1758) through the spawning season. Fish. Res. 104, 73-82.

Dulčić, J., Soldo, A., Jardas, I., 2005. Review of Croatian Selected Scientific Literature on Species Mostly Exploited by the National Small-Scale Fisheries. pp. 134-179 In AdriaMed. Adriatic Sea Small-scale Fisheries. Report of the AdriaMed Technical Consultation on Adriatic Sea Small-Scale. FAO-MiPAF Scientific Cooperation to Support Responsible Fisheries in the Adriatic Sea. GCP/RER/010/ITA/TD15. AdriaMed Technical Documents. 15:184.

El Habouz, H., Recasens, L., Kifani, S., Moukrim, A., Bouhaimi, A., El Ayoubi, S., 2011. Maturity and batch fecundity of the European hake (Merluccius Merluccius, Linnaeus, 1758) in the eastern central Atlantic. Sci. Mar. 75, 447-454.

Ferrer-Maza, D., Lloret, J., Muñoz, M., Faliex, E., Vila, S., Sasal, P., 2014. Parasitism, condition and reproduction of the European hake (Merluccius Merluccius) in the northwestern Mediterranean Sea. ICES J. Mar. Sci. 71, 1088-1099.

Ferreri, R., Basilone, G., D’Elia, M., Traina, A., Saborido-Rey, F., Mazzola, S., 2009. Validation of macroscopic maturity stages according to microscopic histological examination for European anchovy. Mar. Ecol. 30, 181-187.

FishStat Plus, 2012. Universal Software for Fishery Statistical Time Series FAO Fisheries and Aquaculture of the United Nations - 2012. Available:. http://www.fao.org/ fishery/statistics/software/fishstat/en.

Follesa, M.C., Porcu, C., Cabiddu, S., Mulas, A., Deiana, A.M., Cau, A., 2011. Deep-water fish assemblages in the central-western Mediterranean (south Sardinian deepwaters). J. Appl. Ichthyol. 27, 129-135.

GFCM, 2014. Report of the Working Group on Stock Assessment of Demersal Species (WGSAD). Rome, Italy, 24-27 November 2014.

Giannoulaki, M., Valavanis, V.D., Palialexis, A., Tsagarakis, K., Machias, A., Somarakis, S., Papaconstantinou, C., 2008. Modelling the presence of anchovy Engraulis encrasicolus in the Aegean Sea during early summer, based on satellite environmental data. Essential Fish Habitat Mapping in the Mediterranean. Springer, pp. 225-240.

Godo, O.R., Haug, T., 1999. Growth rate and sexual maturity in cod (Gadus morhua) and Atlantic halibut (Hippoglossus Hippoglossus). J. Northwest Atl. Fish. Sci. 25, 115-124.

Gucu, A.C., Bingel, F., 2011. Hake, Merluccius Merluccius L., in the northeastern Mediterranean Sea: a case of disappearance. J. Appl. Ichthyol. 27, 1001-1012.

Harmelin Vivien, M., Mahe, K., Bodiguel, X., Mellon, C., 2012. Possible link between prey quality, condition and growth of juvenile hake (Merluccius Merluccius) in the Gulf of Lions (NW Mediterranean). Cybium 36, 323-328.

Hislop, J.R.G., Robb, A.P., Gauld, J.A., 1978. Observations on effects of feeding level on growth and reproduction in haddock, Melanogrammus aeglefinus (L.) in captivity. J. Fish Biol. 13, 85-98.

Hunter, J.R., Lo, N.C.H., Leong, R.J.H., 1985. Batch fecundity in multiple spawning fishes. NOAA Tech. Rep. NMFS 36, 67-77.

Hunter, J.R., Macewicz, B.J., 1985. Rates of atresia in the ovary of captive and wild northern anchovy, Engraulis mordax. Fish. Bull. U.S. 83, 119-136.

Hutchings, J.A., Reynolds, J.D., 2004. Marine fish population collapses: consequences for recovery and extinction risk. AIBS Bull. 54, 297-309.

ICES, 2007. Report of the Workshop on Sexual Maturity Sampling (WKMAT). ICES CM 2007/ACFM:03. 85 pp..

ICES, 2008. Report of the Workshop on Maturity Ogive Estimation for Stock Assessment (WKMOG). 3-6 June 2008, Lisbon, Portugal. ICES CM2008/ACOM: 33, 72 p..

ICES, 2014. Report of the Workshop on Sexual Maturity Staging of Cod, Whiting, Haddock, Saithe and Hake (WKMSGAD). 4-8 November 2013, San Sebastian, Spain. ICES CM 2013 ACOM:57. 51pp..

Kjesbu, O.S., 1989. The spawning activity of cod, Gadus morhua L. J. Fish Biol. 34, 195-206.

Khoufi, W., Ferreri, R., Jaziri, H., El Fehri, S., Gargano, A., Mangano, S., Ben Meriem, S., Romdhane, M.S., Bonanno, A., Aronica, S., Genovese, S., Mazzola, S., Basilone, G., 2014. Reproductive traits and seasonal variability of Merluccius Merluccius from the Tunisian coast. J. Mar. Biol. Assoc. U.K. 94 (7), 1545-1556.

Korta, M., Domínguez-Petit, R., Murua, H., Saborido-Rey, F., 2010. Regional variability in reproductive traits of European hake Merluccius Merluccius L. populations. Fish. Res. 104, 64-72.

Lloret, J., Demestre, M., Sanchez-Pardo, J., 2008. Lipid (energy) reserves of European hake (Merluccius Merluccius) in the north-western Mediterranean. Vie Milieu 58 , $75-85$.

Lowerre-Barbieri, S.K., Ganias, K., Saborido-Rey, F., Murua, H., Hunter, J.R., 2011. Reproductive timing in marine fishes: variability, temporal scales, and methods. Mar. Coast. Fish. 3 (1), 71-91.

Martín, P., Bahamon, N., Sabatés, A., Maynou, F., Sánchez, P., Demestre, M., 2008. European anchovy (Engraulis encrasicolus) landings and environmental conditions on the Catalan Coast (NW Mediterranean) during 2000-2005. Essential Fish Habitat Mapping in the Mediterranean. Springer, pp. 185-199. 
MedSudMed, 2008. Preliminary Results on Spatial Distribution of Abundance Indices, Nursery and Spawning Areas of Merluccius merluccius and Mullus barbatus in the Central Mediterranean. MedSudMed Technical Documents FAO Rome GCP/RER/ 010/ITA/MSM-TD 19.

Mehault, S., Domínguez-Petit, R., Cervino, S., Saborido-Rey, F., 2010. Variability in total egg production and implications for management of the southern stock of European hake. Fish. Res. 104, 111-122.

Murua, H., Kraus, G., Saborido-Rey, F., Witthames, P., Thorsen, A., Junquera, S., 2003. Procedures to estimate fecundity of marine fish species from field samples in relation to reproductive strategy. J. Northwest Atl. Fish. Sci. 33, 33-54.

Murua, H., Lucio, P., Santurtún, M., Motos, L., 2006. Seasonal variation in egg production and batch fecundity of European hake Merluccius merluccius (L.) in the Bay of Biscay. J. Fish Biol. 69, 1304-1316.

Murua, H., Motos, L., 2006. Reproductive strategy and spawning activity of the European hake Merluccius merluccius (L.) in the Bay of Biscay. J. Fish Biol. 69, 1288-1303.

Murua, H., Motos, L., Lucio, P., 1998. Reproductive modality and batch fecundity of the European hake (Merluccius Merluccius L.) in the Bay of Biscay. Calif. Coop. Ocean. Fish. Investig. Rep. 196-203.

Murua, H., Saborido-Rey, F., 2003. Female reproductive strategies of marine fish species of the North Atlantic. J. Northwest Atl. Fish. Sci. 33, 23-31.

Oliver, P.A., 1991. Dinàmica de la poblaciòn de merluza (Merluccius merluccius L.) de Mallorca (Reclutamento, Crescimento y Mortalidad). Doctoral dissertation. Baleares Islands University, Environmental Biology Department, pp. 391.

Patti, B., Bonanno, A., Basilone, G., Goncharov, S., Mazzola, S., Buscaino, G., Cuttitta, A. Lafuente, J.G., Garcia, A., Palumbo, V., 2004. Interannual fluctuations in acoustic biomass estimates and in landings of small pelagic fish populations in relation to hydrology in the Strait of Sicily. Chem. Ecol. 20, 365-375.

Quattrocchi, F., Maynou, F., 2017. Environmental drivers of sardine (Sardina pilchardus) in the Catalan Sea (NW Mediterranean Sea). Mar. Biol. Res. 13, 1003-1014.

Rago, P.J., 2005. Fishery independent sampling: survey techniques and data analyses. Management techniques for elasmobranch fisheries. In: Musick, J.A., Bonfil, R. (Eds.), Management Techniques for Elasmobranch Fisheries, FAO Fisheries Technical Paper No. 474, pp. 201-215 FAO, Rome.

Ragonese, S., Andreoli, M.G., Bono, G., Giusto, G.B., Rizzo, P., Sinacori, G., 2004 Overview of the available biological information on demersal resources of the Strait of Sicily. MedSudMed Technol. Doc. 2, 67-74.

Reading, B.J., Sullivan, C.V., Schilling, J., 2017. Vitellogenesis in fishes. In: Ferrell, A.P. (Ed.), Encyclopedia of Fish Physiology: From Genome to Environment. TheReproductive Organs and Processes. Reference Module in Life Sciences. Elsevier, Maryland Heights, MO, pp. 1-12.

R Core Team, 2017. R: A Language and Environment for Statistical Computing.
Available:. https://www.R-project.org/.

Recasens, L., Chiericoni, V., Belcari, P., 2008. Spawning pattern and batch fecundity of the European hake (Merluccius merluccius (Linnaeus, 1758)) in the western Mediterranean. Sci. Mar. 72, 721-732.

Recasens, L., Lombarte, A., Morales-Nin, B., Torres, G.J., 1998. Spatiotemporal variation in the population structure of the European hake in the NW Mediterranean. J. Fish Biol. 53, 387-401.

Reňones, O., Messuti, E., Morales-Nin, B., 1995. Life history of the red mullet Mullus surmuletus from the bottom-trawl fishery off the Island of Majorca (north-west Mediterranean). Mar. Biol. 123, 411-419.

Sànchez, P., Martìn, P., 1985. Talla de primera madurez y selectivitad en algunas especies demersales de interés comercial del litoral catalàn. Informes Técnicos. Instituto Español De Oceanografía. 100, 19-27.

Sarano, F., 1984. Cycle ovarien du merlu, Merluccius merluccius, poisson a ponte fractionnee. Rev. des Trav. l'Institut des Pech. Marit. 48, 65-76.

Soykan, O., Ilkyaz, A.T., Metin, G., Kinacigil, H.T., 2015. Age, growth and reproduction of European hake (Merluccius merluccius (Linn., 1758)) in the Central Aegean Sea, Turkey. J. Mar. Biol. Assoc. U. K. 95 (4), 829-837.

Stergiou, K.I., Christou, E.D., Georgopoulous, D., Zenetos, A., Souvermezoglou, C., 1997. The Hellenic seas: physics, chemistry, biology and fisheries. In: Ansell, A.D., Gibson, R.N., Barnes, M. (Eds.), Oceanography and Marine Biology: an Annual Review. UCL Press, pp. 415-538.

Tomkiewicz, J., Morgan, M.J., Burnett, J., Saborido-Rey, F., 2003. Available information for estimating reproductive potential of Northwest Atlantic groundfish stocks. J. Northwest Atl. Fish. Sci. 33, 1-21. https://doi.org/10.2960/J.v33.a1.

Trippel, E.A., 1995. Age at maturity as a stress indicator in fisheries. Bioscience 45, 759-771.

Tugores, M.P., Giannoulaki, M., Iglesias, M., Bonanno, A., Tičina, V., Leonori, I., Machias, A., Tsagarakis, K., Diaz, N., Giraldez, A., 2011. Habitat suitability modelling for sardine Sardina pilchardus in a highly diverse ecosystem: the Mediterranean Sea. Mar. Ecol. Prog. Ser. 443, 181-205.

Ungaro, N., Rizzi, E., Marano, G., 1993. Note sulla biologia e pesca di Merluccius merluccius (L.) nell'Adriatico pugliese. Biol. Mar. Mediterr. 1, 329-334.

Vitale, F., Cardinale, M., Svedäng, H., 2005. Evaluation of temporal development of the ovaries in Gadus morhua from the Sound and Kattegat, North Sea. J. Fish Biol. 67, 669-683.

Vitale, F., Svedäng, H., Cardinale, M., 2006. Histological analysis invalidates macroscopically determined maturity ogives of the Kattegat cod (Gadus morhua) and suggests new proxies for estimating maturity status of individual fish. ICES J. Mar. Sci. $63,485-492$. 